\title{
Quarterly Technical Progress Report - Investigation of Syngas Interaction in Alcohol Synthesis Catalysts
}

\author{
Quarterly Report \\ June 1 - August 31, 1997
}

By

Murty A. Akundi

Work Performed Under Contract No.: DE-FG22-93MT93010

\author{
For \\ U.S. Department of Energy \\ Office of Fossil Energy \\ Federal Energy Technology Center \\ P.O. Box 880 \\ Morgantown, West Virginia 26507-0880
}

By

Xavier University of Louisiana

New Orleans, Louisiana 70125 


\section{Disclaimer}

This report was prepared as an account of work sponsored by an agency of the United States Government. Neither the United States Government nor any agency thereof, nor any of their employees, makes any warranty, express or implied, or assumes any legal liability or responsibility for the accuracy, completeness, or usefulness of any information, apparatus, product, or process disclosed, or represents that its use would not infringe privately owned rights. Reference herein to any specific commercial product, process, or service by trade

name, trademark, manufacturer, or otherwise does not necessarily constitute or imply its endorsement, recommendation, or favoring by the United States Government or any agency thereof. The views and opinions of authors expressed herein do not necessarily state or reflect those of the United States Government or any agency thereof. 


\title{
QUARTERLY TECHNICAL PROGRESS REPORT
}

\author{
Submitted to U.S Department of Energy
}

GRANT TITLE: Investigation of Syngas Interaction in alcohol Synthesis Catalysts

GRANT NO:

DE-FG22-93MT93010--14 (XU: 235-860)

STARTING DATE: 09-01-93

ENDING DATE: $\quad$ 08-31-97

PROJECT DIRECTOR: $\quad$ MURTY A. AKUNDI

PHYSICS/ENGINEERING DEPARTMENT

INSTITUTION: $\quad$ Xavier University of Louisiana

New Orleans, La 70125

*U.S. / DOE Patent Clearance is not required prior to the publication of this document 


\section{Quarterly Technical progress Report}

(Period January 1 to March 31, 1997)

This report presents the work done on " Investigation of Syngas Interaction in Alcohol Synthesis Catalysts" during the last quarter. The major activity during this period is on FTIR absorption studies of $\mathrm{Co} / \mathrm{Cr}$ catalysts using $\mathrm{CO}$ as a probe molecule. The results of this work have been presented at the National Council of Undergraduate research conference. The paper will be published in the conference proceedings. A copy of the paper presented to this proceedings is enclosed.

One of the students, Mr. Caribee Collier will be graduating from Xavier University of Louisiana in May 1997 and will be attending graduate school this fall. Two new students will start learning these techniques and will be working on this project this summer.

In the coming months FTIR studies on Iron-Zinc catalysts will be investigated. Magnetization studies on these samples have been completed and we plan to correlate FTIR data with magnetic data. 
CO Adsorption on Cobalt Particles Supported on Chromia

- An FTIR Study

Caribee Collier and Agegnehu Tsega

Physics Engineering Department

Xavier University of Louisiana

New Orleans, Louisiana 70125

Faculty Advisors:

Murty A. Akundi (Xavier University of Louisiana)

and

A.N. Murty (Physics Department, Grambling State University,

Grambling LA 71245)

Transition metals cobalt and copper play significant roles in the conversion of syngas $\left(\mathrm{CO}+\mathrm{H}_{2}\right)$ to liquid fuels. With a view to examine the nature of interaction between $\mathrm{CO}$ and metal, the FTIR spectra of $\mathrm{CO}$ adsorbed on Co$\mathrm{Cr}_{2} \mathrm{O}_{3}$ composites were investigated. The results indicate that as cobalt loading increases, the intensity of the $\mathrm{CO}$ adsorption bands increase and several vibrational modes seem to be promoted. Heat treatment of the sample revealed two distinct processes of adsorption. Bands due to physisorption disappeared while bands due to chemisorption not only increased in intensity but persisted even after desorption. It seems that the physisorption process is more active when the catalyst is fresh and is hindered when carbidic/carbonyl formations occur on the metal surfaces.

\section{INTRODUCTION:}

The study of $\mathrm{CO}$ adsorption on $\mathrm{Co}-\mathrm{Cr}_{2} \mathrm{O}_{3}$ alloy by infra-red spectroscopy and magnetic methods is of interest for various reasons.

(i) A complete description of gas-metal interactions requires information on both the adsorbate and the absorbent, and this can be achieved by using simultaneously these two techniques.

(ii) $\mathrm{CO}$ is a good probe molecule for chemisorption studies because of its associative or dissociative nature when adsorbed on metal. This study could provide information on the electron charge transfer mechanism of the probe molecule. 
(iii) Magnetization studies provide information on the changes in the metallic charge distribution character of the composite sample.

Very little work [1-2] has been done on infrared spectra of carbon monoxide adsorbed on cobalt. . To our knowledge no FTIR studies of $\mathrm{CO}$ adsorption on Co$\mathrm{Cr}_{2} \mathrm{O}_{3}$ have been made nor any correlation results reported between magnetization and FTIR data. This paper presents the results of the magnetic and FTIR measurements on $\mathrm{Co}-\mathrm{Cr}_{2} \mathrm{O}_{3}$ metal composite.

\section{EXPERIMENTAL METHODS:}

Magnetic measurements of the composite sample were made using a Digital Measurement Systems (Boston, MA) DMS-880 vibrating sample magnetometer and Zero-field NMR spectra were obtained using a modified WILK's NQR spectrometer described else where [3].

The FTIR Spectrometer and DRIFT System consists of Mattison Research series FTIR spectrometer, equipped with an MCT detector operable in the mid IR region (4000-600 $\mathrm{cm}^{-1}$ ), a diffuse reflectance accessory, an environmental chamber and an automatic temperature controller.

An optical diagram of the diffuse reflection attachment is shown in Fig.1. The praying mantis design incorporates two $6: 190^{\circ}$ off -axis ellipsoidal mirrors, $\mathrm{M}_{3}$ and $\mathrm{M}_{4}$, which subtend $20 \%$ of the 2 pi solid angle. These ellipsoids are arranged with a common focal point $S$. Mirrors $\mathrm{M}_{1}$ and $\mathrm{M}_{2}$ transfer the IR beam from the spectrometer to the first of these ellipsoids $\mathrm{M}_{3}$. This ellipsoid focuses the beam onto the sample, S. The second ellipsoid collects the radiation diffusely reflected from the sample. This radiation is then directed by mirrors $M_{5}$ and $M_{6}$ towards the detector. The environmental chamber (fig.2), a stainless steel reaction chamber, consists of a sample cup to load the sample, two windows at the entrance and exit positions for the incident and reflected infrared radiations. A third window is provided at the back of the chamber to illuminate or view the sample. In addition two entry ports are provided for vacuum and gas and another set for water circulation. The environmental chamber is connected to an automatic temperature controller that can be raised up to $600^{\circ} \mathrm{C}$. 


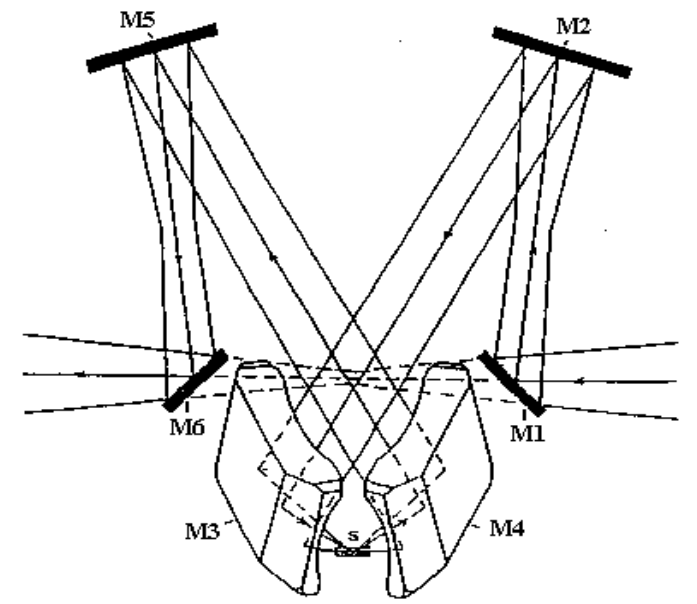

Fig. 1 Optical Arrangement of the DRIFT System

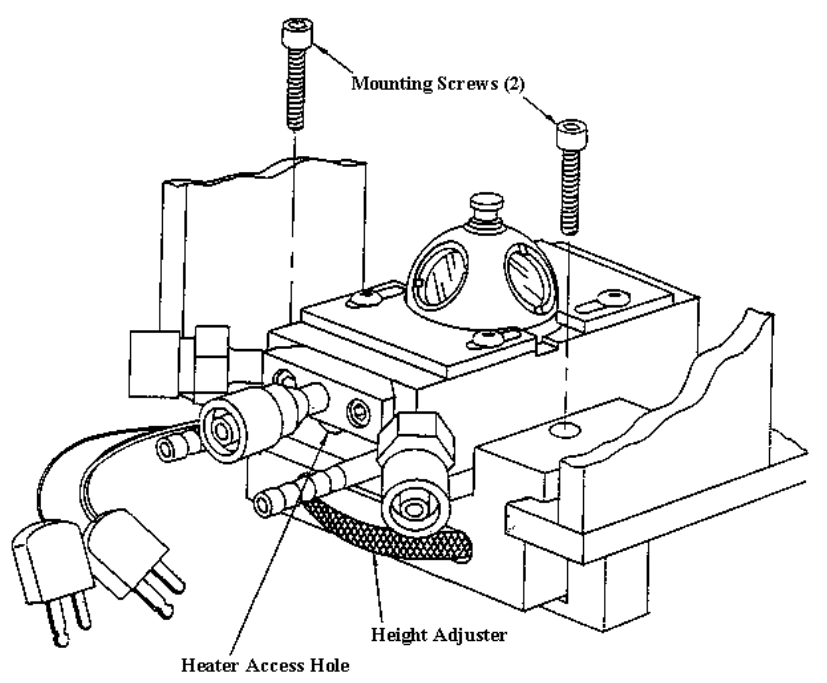

Fig. 2 Environmental Chamber

$\underline{\text { Sample preparation: }}$

All the samples were prepared by co-precipitation of nitrates in a 7-8 $\mathrm{pH}$ sodium hydroxide solution at $80^{\circ} \mathrm{C}$. The precipitate is washed, dried at $80^{\circ} \mathrm{C}$ for 18 hours, calcined at $350^{\circ} \mathrm{C}$ for 18 hours and reduced in a flowing stream of hydrogen at $350^{\circ} \mathrm{C}$ for 18 hours. Hydrogen was out gassed while reducing the temperature to $250^{\circ} \mathrm{C}$. At this temperature carbon monoxide was admitted for 30 minutes and then while continuously flowing carbon monoxide the temperature was reduced step wise to $25^{\circ} \mathrm{C}$ and spectra were taken at each temperature. At $25^{\circ} \mathrm{C} \mathrm{CO}$ was out gassed and the temperature was increased in reverse order to obtain the desorbed spectra of CO. Four different samples $(0.5<\mathrm{Co} / \mathrm{Cr}<16.0)$ were used in this investigation to study the effect of metal ratio on the $\mathrm{CO}$ stretching frequencies. FTIR spectra for each sample were taken three times for reproducibility of the results. All the spectra obtained were recorded with 500 scan accumulation at a resolution of $4 \mathrm{~cm}^{-1}$.

\section{RESULTS AND DISCUSSION:}

Magnetization studies made on three samples $\mathrm{Co} / \mathrm{Cr} \leq 2.0$ indicate that about $75 \%$ of cobalt is locked in $\mathrm{Co}_{-} \mathrm{Cr}_{2} \mathrm{O}_{4}$ type spinel structures. Only $25 \%$ of the loaded metal appears to be amenable for reduction. NMR spectra did not reveal any inter-metallic interaction between cobalt and chromium. NMR lines occurred in the expected positions for pure cobalt [4].

FTIR results are presented in Table 1 and Figs. 3-5. Frequency measurements are accurate within $\pm 4 \mathrm{~cm}^{-1}$. 


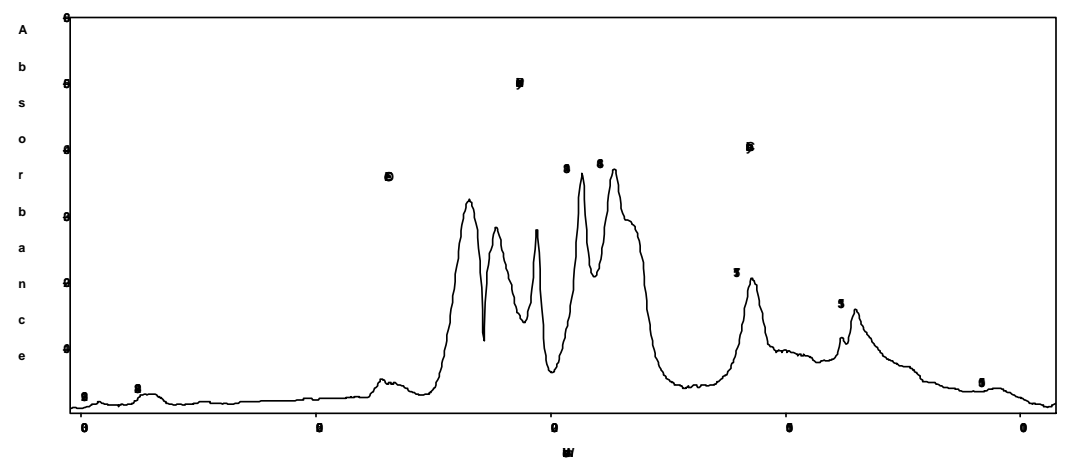

Fig. $3 \mathrm{Co} / \mathrm{Cr}(16.0)+\mathrm{CO} @ 250^{\circ} \mathrm{C}$

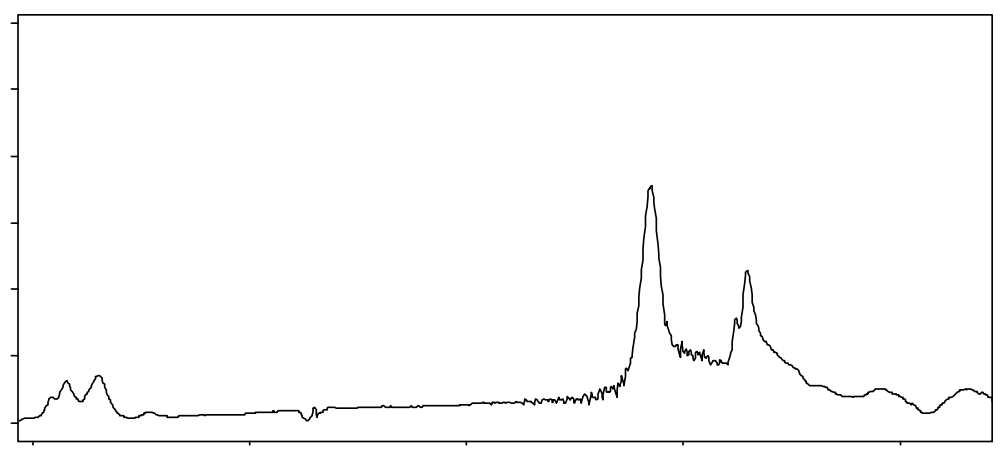

Fig. 4 Co/Cr (16.0) CO Desorbed @ 250 ${ }^{\circ} \mathrm{C}$

In all the spectra recorded we did not observe any significant changes due to temperature variation.

The observed spectra fall in to three distinct regions.
A. $2900-2750 \mathrm{~cm}^{-1}$
B. $2000-1650 \mathrm{~cm}^{-1}$
C. $1600-850 \mathrm{~cm}^{-1}$ 


\begin{tabular}{|c|c|c|c|c|c|c|c|}
\hline \multicolumn{2}{|c|}{0.5} & \multicolumn{2}{|c|}{3.0} & \multicolumn{2}{|c|}{8.0} & \multicolumn{2}{|c|}{16.0} \\
\hline Adsorbed & Desorbed & Adsorbed & Desorbed & Adsorbed & Desorbed & Adsorbed & Desorbed \\
\hline 2957 & 2960 & 2954 & 2963 & & 2960 & 2962 & 2962 \\
\hline 2870 & 2874 & 2861 & 2879 & & & & \\
\hline 2848 & 2854 & & 2846 & & 2838 & 2846 & \\
\hline 2803 & & 2803 & & & & & \\
\hline & & & & 2031(PA) & & 2028(PA) & \\
\hline 2002(PA) & & 2004(PA) & & & & & \\
\hline & & & & 1959(PA) & & 1932(PA) & \\
\hline & & & & & & 1863(PA) & \\
\hline 1657(PA) & & 1645 (PA) & & $1635(\mathrm{PA})$ & & & \\
\hline 1599 & 1605 & 1585 & 1597 & 1549 & 1561 & 1576 & 1580 \\
\hline 1364 & 1343 & 1371 & 1362 & 1354 & 1368 & 1369 & 1352 \\
\hline 1064 & 1053 & 1065 & 1054 & 1056 & 1056 & 1049 & 1043 \\
\hline 849 & 844 & 846 & 851 & 849 & 846 & 858 & 846 \\
\hline
\end{tabular}

PA - Physisorbed Bands Weakly Bonded to Metallic Co

The two sharp peaks (Fig. 3) at 2170 and 2117 (P and R branch heads of $2143 \mathrm{~cm}^{-1}$ of $\mathrm{CO}$ band) are due to free gaseous CO molecule. The bands in the region $2000-1650 \mathrm{~cm}^{-1}$ region seem to be due to CO linearly bonded to Cobalt [5]. Desorption of $\mathrm{CO}$ causes the disappearance of these bands. Figs. 3 and 4 clearly illustrate this effect of CO-desorption. These lines could be due to physisorption processes ranging from weak electrostatic interaction to bonding with one, two, or three surface cobalt metal atoms. The physisorbed bands seems to be dependent on temperature, metal ratio and the time of CO flow. The bands in the $1600-850 \mathrm{~cm}^{-}$ ${ }^{1}$ region are persistent even after desorption of $\mathrm{CO}$. This might be, as suggested by earlier investigators [6-7] due to the formation of $\mathrm{CO}_{2}$ which is stabilized in the matrix as a $\mathrm{CO}_{3}{ }^{2-}$ species. The bands in the region $2900-2750 \mathrm{~cm}^{-1}$ are also persistent after desorption and may result due to different chemical interactions between $\mathrm{CO}$ and $\mathrm{Co}-\mathrm{Cr}_{2} \mathrm{O}_{3}$ matrix. We noticed that carbonyls formation takes place when the catalyst is exposed to $\mathrm{CO}$ even at room temperature. Though this retards physisorption process, deactivation of the catalyst may not occur and the metal carbonyls formed might play active roles in the catalytic process.

The $1600 \mathrm{~cm}^{-1}$ band seems to be sensitive to the metal ratio and shows a downward trend as Co content increases up to a certain point. Further increase of Co metal in the sample $\mathrm{Co} / \mathrm{Cr}=16.0$, this band became sharper and more intense and shifted back to higher wave numbers (Fig.5). It is difficult to ascertain 
whether it is a frequency shift in the stretching frequency of a a specific carbonyl band or different carbonyl structures occur as more cobalt appears in the matrix. Metal ratio appears to have no significant effect on the other bands in this region.

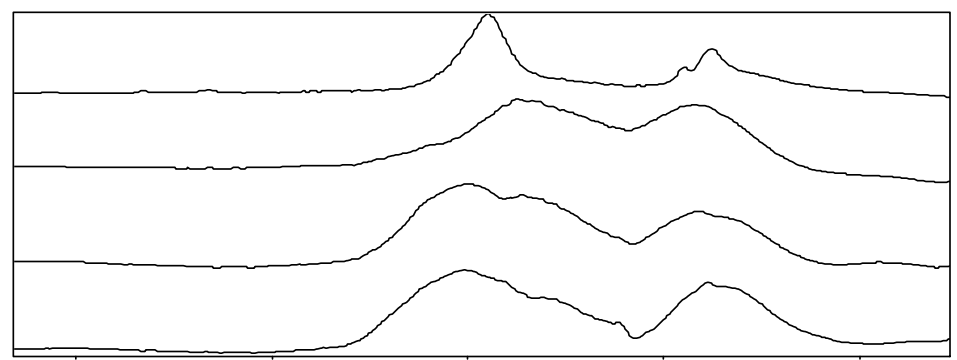

\section{CONCLUSIONS:}

Our NMR studies show no noticeable shift in the NMR lines of cobalt indicating that no significant intermetallic interactions occur between metal and support. Magnetization studies indicate that at lower metal loading $\mathrm{Co} / \mathrm{Cr} \leq 2$, most of the cobalt could be locked in spinel structures and only the metal appears to be amenable for reduction. IR spectra on all the samples studied $(0.5<\mathrm{Co} / \mathrm{Cr}<$ 16.0 ) show no measurable changes due to temperature variation either in the absorption or description process. At low Co ratios physisorption bands formed could be due to weak linear $\mathrm{CO}$ - metal bonding. Increase in cobalt metal content seems to enhance the physisorption process and $\mathrm{CO}$ bonding might be occurring with multiple surface metal atoms. In all the samples studied we have observed metal carbonyl bands indicating that a chemical reaction occurs and $\mathrm{CO}_{2}$ formed may be stabilized in the matrix as $\mathrm{CO}_{3}{ }^{2-}$ species. Further studies might provide better insights into the catalytic mechanisms involved.

Acknowledgments:

The authors wish to acknowledge the financial support from the Department of Energy (Grant \#DE-FG22-93MT93010) and the National Science Foundation (Grant \#HRD292527002). The authors wish to thank Shalarma Davis for her help in preparing the samples.

References: 
1. K. Mohana Rao, D.Scarano, G. Spoto and A. Zecchina, Surface Sci. , 319 (1988)

2. K. Sato, Y. Inoue, I. Kojima, E. Miyajaki, and I. Yasumori, J. Chem. soc. Faraday Trans I. , 841 (1984)

3. A.N. Murty, A.A. Williams, R.T. Obermyer, V.U.S. Rao, and R.J.Gormley, " NMR Studies of Cobalt-Thoria-ZSM-5 catalysts" Catalysis p 73-80, 1987, J.W.Ward Ed. Elseiver, Amstredam 1988

4. A.N. Murty, M. Seamster, and D. Paulson, LAS conference, Baton Rouge, La Feb. 91.

5. P. Hollins and J. Pritchaard, in: Vibrational Spectroscopy of Adsorbates, ED. R.F. Willis, Vol 15 of springer series in chemical physics (Springer, Berlin, 1980) p. 125

6. L.H. Little, Infrared Spectra of Adsorbed Species ( Academic press, New York, 1966) p. 76

7. K. Nakamoto, Infrared Spectra of Inorganic and Coordination Compounds (Wiley-interscience, New York, 1970) p. 169 